\title{
ADOPTA LA ASAMBLEA GENERAL DE LA ONU LA DECLARACION DE LAS NACIONES UNIDAS SOBRE CLONACIÓN HUMANA
}

La Asamblea General de Naciones Unidas, en su sesión del 23 de marzo de 2005 adoptó — por 84 votos a favor (incluyendo a México), 34 en contra y 37 abstenciones - la Resolución 59/280 denominada Declaración de las Naciones Unidas sobre la Clonación Humana.

Recordando su resolución 53/152, de 9 de diciembre de 1998, en la que hizo suya la Declaración Universal sobre el Genoma Humano y los Derechos Humanos:

\section{DECLARACIÓN DE LAS NACIONES UNIDAS \\ SOBRE LA CLONACIÓN HUMANA}

La Asamblea General, Guiándose por los propósitos y principios de la Carta de las Naciones Unidas, biológicas en rápida evolución pueden plantear con respecto a la dignidad del género humano, los derechos humanos y las libertades fundamentales de la persona,

Reafirmando que la aplicación de las ciencias biológicas debe tratar de mitigar los sufrimientos y mejorar la salud de la persona y la especie humana en general, Haciendo hincapié en que el avance científico y técnico de las ciencias biológicas debe promoverse salvaguardando el respeto de los derechos humanos y el beneficio de todos,

Consciente de los graves peligros médicos, físicos, psicológicos y sociales que la clonación humana puede entrañar para quienes participan en ella, y consciente también de la necesidad de impedir la explotación de la mujer,

Convencida de la urgente necesidad de prevenir los posibles peligros de la clonación humana para la dignidad humana, 
Declara solemnemente lo siguiente:

a) Los Estados Miembros habrán de adoptar todas las medidas necesarias para proteger adecuadamente la vida humana en la aplicación de las ciencias biológicas;

b) Los Estados Miembros habrán de prohibir todas las formas de clonación humana en la medida en que sean incompatibles con la dignidad humana y la protección de la vida humana;

c) Los Estados Miembros habrán de adoptar además las medidas necesarias a fin de prohibir la aplicación de las técnicas de ingeniería genética que pueda ser contraria a la dignidad humana;

d) Los Estados Miembros habrán de adoptar medidas para impedir la explotación de la mujer en la aplicación de las ciencias biológicas;

e) Los Estados Miembros habrán también de promulgar y aplicar sin demora legislación nacional para poner en práctica los apartados $a$ ) a $d$ );

f) Los Estados Miembros habrán además de tener en cuenta, en su financiación de la investigación médica, incluidas las ciencias biológicas, cuestiones acuciantes de alcance mundial como el VIH-SIDA, la tuberculosis y la malaria, que afectan particularmente a los países en desarrollo. ${ }^{1}$

\section{La posición de México}

En la negociación de este instrumento, México se guió por la necesidad de alcanzar un consenso en un tema de interés mundial, que asegurara el respeto a la dignidad humana en la aplicación de la ciencia. Corresponderá ahora a las legislaciones nacionales precisar los alcances de la declaración, incluyendo los términos que utiliza, de conformidad con los criterios culturales, filosóficos y religiosos que predominen en cada sociedad y el respeto de los derechos humanos reconocidos por la comunidad internacional.

A pesar de las divisiones y las dificultades inherentes al tema, la Declaración de las Naciones Unidas sobre Clonación Humana contribuirá a la discusión nacional del tema en los distintos países que aún no cuentan con legislación al respecto. ${ }^{2}$

\section{Comentario}

En el marco de la revolución biotecnológica en curso, la Organización de Naciones Unidas promovió negociaciones rumbo a un tratado in-

1 Fuente: http://daccessdds.un.org/doc/UNDOC/GEN/N04/493/09/PDF/N0449309.pdf?Open Element

2 Véase http://www.sre.gob.mx/comunicados/comunicados/2005/marzo/b_040.htm 
ternacional sobre la investigación genómica que pueda llegar a la clonación humana. La idea era crear un marco jurídico general y obligatorio para todos los Estados. La importancia del tema concierne a todos ellos, aun los subdesarrollados que no cuentes con una biotecnología desarrollada (los científicos y laboratorios pueden fácilmente moverse a Estados en donde haya condiciones jurídicas propicias para sus investigaciones, es decir donde no haya prohibiciones ni obstáculos jurídicos para la clonación). Desafortunadamente, los intereses de las grandes potencias hicieron abortar este esfuerzo y en su lugar, como nota de consolación, se propuso una Resolución de la AG que según la ortodoxia es meramente una recomendación, sin carácter vinculante, dando por resultado un documento lleno de disposiciones bastante generales, buenas intenciones, sujetas su efectividad a la buena razón de los Estados.

La generalidad de la resolución no permite que se haga diferencia entre la clonación de carácter terapéutico y la clonación humana total, más bien se inclina a prohibir todo tipo de clonación (los Estados miembros habrán de prohibir todas las formas de clonación humana en la medida en que sean incompatibles con la dignidad humana y la protección de la vida humana). Esto es trascendente ya que, aunque la resolución trata de establecer un equilibrio entre ciencia y derechos humanos ("Haciendo hincapié en que el avance científico y técnico de las ciencias biológicas debe promoverse salvaguardando el respeto de los derechos humanos y el beneficio de todos"), la ausencia de diferenciación puede constituirse en un obstáculo a la investigación científica.

La legislación que adopten los Estados deberá precisamente establecer ese equilibrio entre ciencia y derechos humanos, no constituirse en un obstáculo para el desarrollo científico, ni permitir la violación de los derechos humanos y cuidando se cumpla el aspecto social de la investigación sobre todo tratándose de la salud.

Manuel BECERRA RAMÍREZ*

* Investigador del Instituto de Investigaciones Jurídicas de la UNAM. 